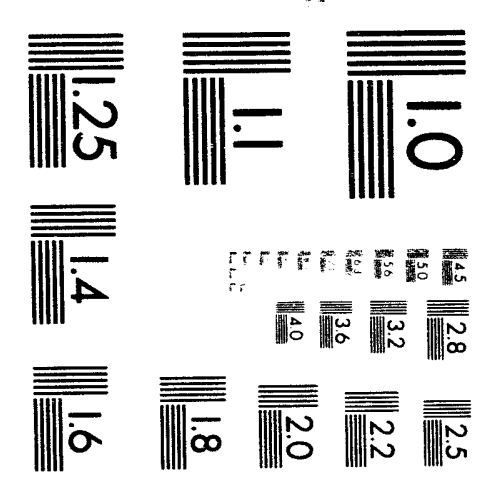



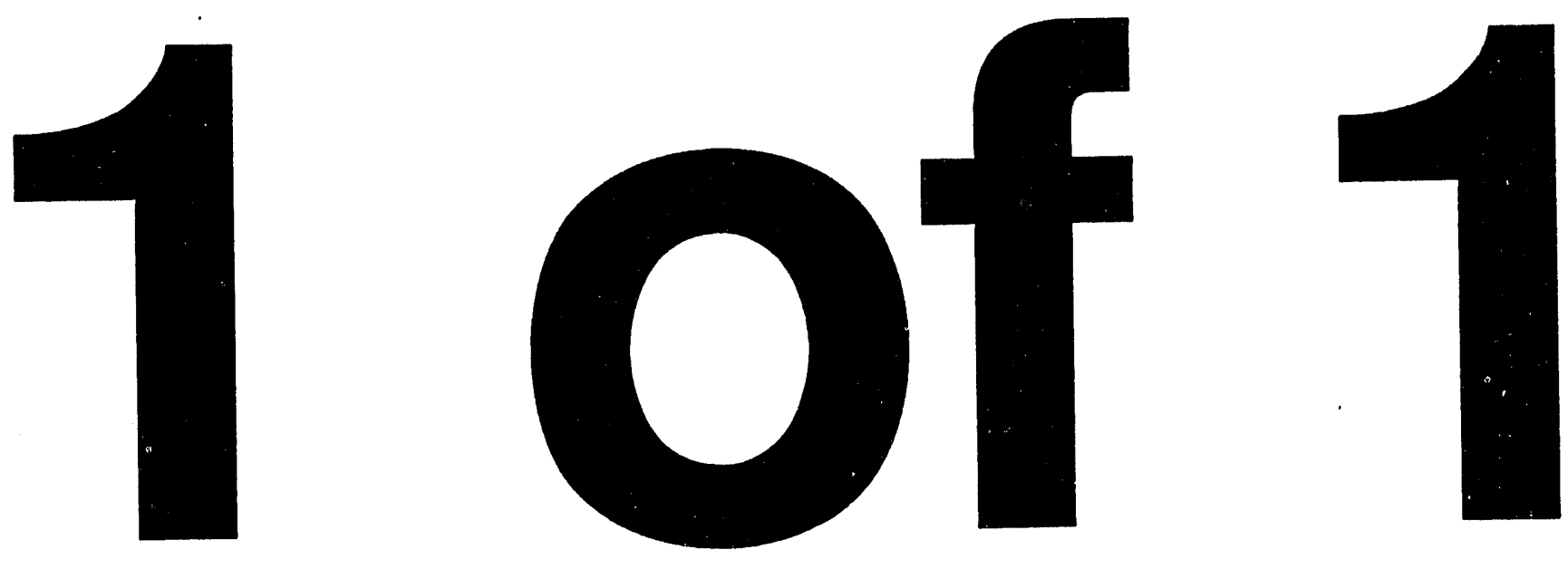


\title{
PREDICTION OF THE ONSET OF SIGNIFICANT VOID IN TRANSIENT SUBCOOLED FLOW BOILING (U)
}

\author{
by
}

S. C. LEE, S. G. BANKOFF

ISSUED: JUNE, 1993

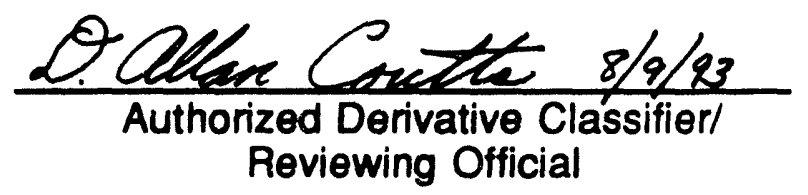

SRTC SAVANNAH RIVER TECHNOLOGY CENTER, AIKEN, SC 29808 Westinghouse Savannah River Corporation Prepared for the U.S. Department of Energy under Contract DE-AC09-89SR18035 
Document:

Title:

Contract:

Task title:
WSRC-TR-93-405

PREDICTION OF THE ONSET OF SIGNIFICANT VOID IN TRANSIENT SUBCOOLED FLOW BOILING (U)

AX 811457

\section{Approvals}

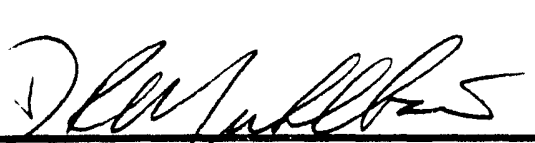

D. R. Mưhtbaler, hesponsible Manager

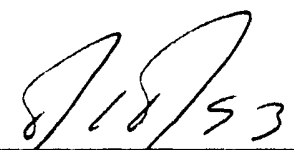

$$
91 \text { Hasit }
$$




\section{DISCLAIMER}

This report was prepared as an account of work sponsored by an agency of the United States Government. Neither the United States Government nor any agency thereof, nor any of their empluyees, makes any warranty, express or implied, or assumes any legal liability or responsibility for the accuracy, completeness, or usefulness of any information, apparatus, product, or process disclosed, or represents that its use would not infringe privately owned rights. Reference herein to any specific commercial product, process, or service by trade name, trademark, manufacturer, or otherwise does not necessarily constitute or imply its endorsement, recommendation, or favoring by the United States Government or any agency thereof. The views and opinions of authors expressed herein do not necessarily state or reflect those of the United States Government or any agency thereof.

This report has been reproduced directly from the best available copy.

Available to DOE and DOE contractors from the Office of Scientific and Technical Information, P. O. Box 62, Oak Ridge, TN 37831; prices available from (615) 576-8401.

Available to the public from the National Technical Information Service, U. S. Department of Commerce, 5285 Port Royal Rd., Springfield, VA 22161. 


\title{
SRTC Perspective
}

\author{
D. A. Coutts \\ Senior Engineer
}

The coolant in the Savannah River Site (SRS) production nuclear reactor assemblies is circulated as a subcooled liquid under normal operating conditions. This coolant is evenly distributed throughout multiple annular flow channels with a uniform pressure profile across each coolant flow channel. During the postulated Loss of Coolant Accident (LOCA), which is initiated by a hypothetical guillotine pipe break, the coolant flow though the reactor assemblies is significantly reduced. The flow reduction and accompanying power reduction (after shutdown is initiated) occur in the first 1 to 2 seconds of the LOCA. This portion of the LOCA is referred to as the flow instability (FI) phase (1).

The reactor assemblies are subject to a type of FI known as a Ledinegg flow excursion. This type of instability is common in low pressure subcooled flow channels that exhibit a demand curve with a negative sloped region and a relative maximum and minimum as shown in Figure 1. The relative minimum is the result of the flow acceleration created by the change in fluid density, and an increase in the frictional pressure loss created by vapor nucleating on the heater surface and effectively increasing the flow channel roughness. The postulated LOCA can initiate such a flow excursion.

Assembly power limits are calculated for LOCA conditions using the FLOWTRAN-FI code. The code calculates a dimensionless ratio known as the Stanton number at each axial position in the channel through the course of the transient. This Stanton number was introduced by Saha and Zuber (2) to describe the onset of significant void (OSV) in channels where subcooled nucleate boiling is present.

$$
S t=\frac{\phi}{G c_{p}\left(T_{\text {sat }}-T_{b}\right)}
$$

where:

$$
\begin{aligned}
& \phi \quad=\text { local heat flux } \\
& G=\text { mass velocity } \\
& C_{p}=\text { liquid specific heat } \\
& T_{\text {sat }}=\text { saturation temperature } \\
& T_{b}=\text { bulk liquid temperature }
\end{aligned}
$$

The Stanton number will vary both with time and position in the assembly. The reactor operating power is limited to preclude Stanton numbers in excess of 0.00455 during the LOCA. This value is 70 percent of the 0.065 value proposed by Saha and Zuber (2). This difference is a safety margin that accounts for data and calculation uncertainties.

OSV and the Stanton number criterion are steady-state concepts. It is desirable to know the uncertainties associated with their application to a transient process. The Experimental Thermal-Hydraulics Group of the Nuclear Engineering Section contracted SGB Associates of Evanston, IL to study the transient FI process. This work has been completed. Table 1 presents a summary of the reports produced during this study. 


\section{References}

1. Action Plan to Upgrade Thermal-Hydraulic Limits for Savannah River Site Production Reactors (U). 30 June 1989. WSRC-RP-89-373.

2. Saha, P., and N. Zuber, 1974, Point of Net Vapor Generation and Vapor Void Fraction in Subcooled Boiling. In Proceedings of the 5th International Heat Transfer Conforence, Tokyo, Japan, September 3-7, 1974, 175-79. 


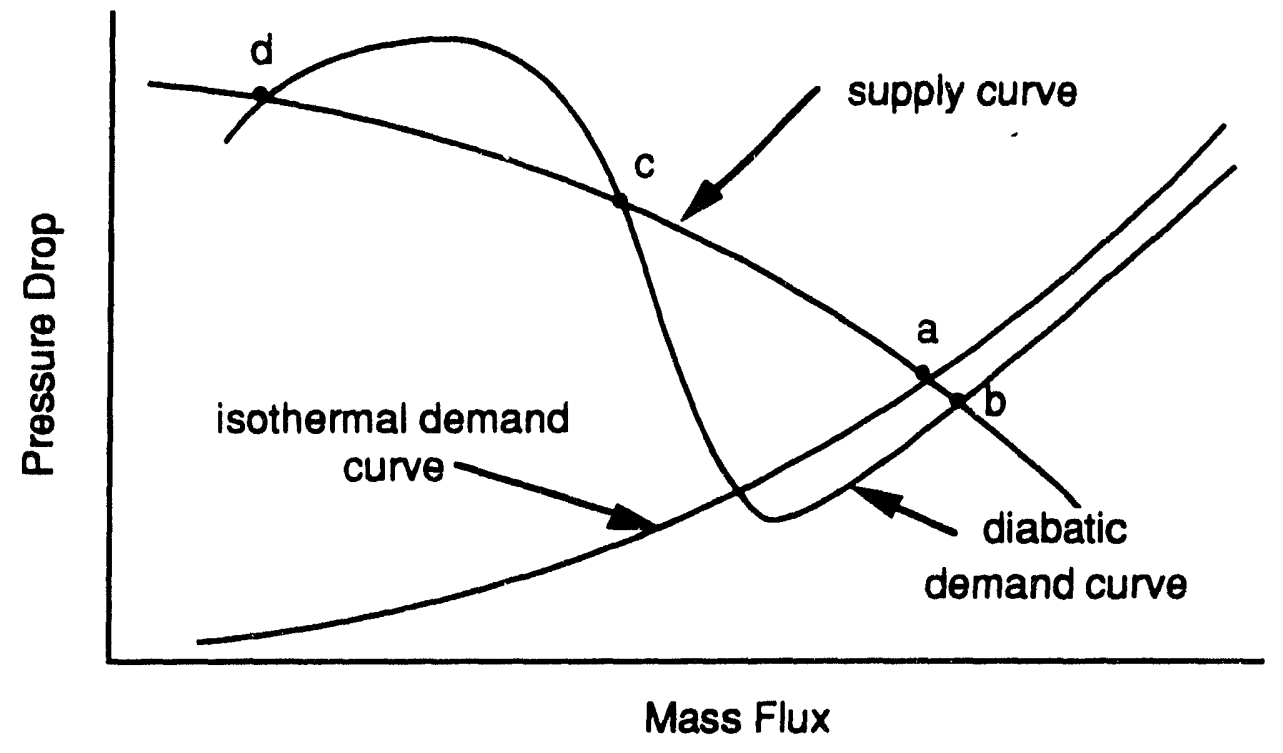

Figure 1. Demand curves for subcooled isothermal and diabatic systems

Table 1--Reports prepared as part of AX-1811457

\begin{tabular}{|c|c|c|}
\hline Authors & Title & Document number \\
\hline $\begin{array}{l}\text { Bankoff, S. G., S. C. Le日, } \\
\text { \& A. Knaani }\end{array}$ & $\begin{array}{l}\text { Literature Review on Forced- } \\
\text { Convection Subcooled Boiling }\end{array}$ & WSRC-TR-91-98 \\
\hline $\begin{array}{l}\text { Lee, S. C., \& S. G. } \\
\text { Bankoff }\end{array}$ & $\begin{array}{l}\text { Stability of Forced Convection } \\
\text { Subcooled Boiling }\end{array}$ & WSRC-TR-92-233 \\
\hline $\begin{array}{l}\text { Dorra, H., S. C. Lee, and } \\
\text { S. G. Bankoff }\end{array}$ & $\begin{array}{l}\text { A Critical Review of Predictive Models } \\
\text { for the Onset of Significant Void in } \\
\text { Forced-Convection Subcooled Boiling }\end{array}$ & WSRC-TR-93-404 \\
\hline $\begin{array}{l}\text { Le日, S. C., and S. G. } \\
\text { Bankoff }\end{array}$ & $\begin{array}{l}\text { Prediction of the Onset of Significant } \\
\text { Void in Transient Subcooled Flow } \\
\text { Boiling }\end{array}$ & WSRC-TR-93-405 \\
\hline $\begin{array}{l}\text { Gehrke, Volker, \& S. G. } \\
\text { Bankoff }\end{array}$ & $\begin{array}{l}\text { Stability of Forced-Convection } \\
\text { Subcooled Boiling in Steady-State and } \\
\text { Transient Annular Flow }\end{array}$ & WSRC-TR-93-406 \\
\hline $\begin{array}{l}\text { Dorra, H., S. C. Lee, and } \\
\text { S. G. Bankoff }\end{array}$ & $\begin{array}{l}\text { Onset of Significant Void in Internal } \\
\text { Flow, Forced Convection, Subcooled } \\
\text { Boiling }\end{array}$ & WSRC-TR-93-407 \\
\hline
\end{tabular}




\section{Prediction of the Onset of Significant Void in Transient Subcooled Flow Boiling ${ }^{1}$}

S. C. Lee ${ }^{2}$ and S. G. Bankoff

Chemical Engineering Department

Northwestern University

Evanston, IL 60208-3120

June 30, 1992

${ }^{1}$ Work supported by Savannah River Laboratory, Westinghouse Savannah River Co., Aiken, S.C.

${ }^{2}$ Visiting Scholar, Present address: Department of Mechanical Engineering, Yeungnam University, Gyongsan, Korea 712-749 


\begin{abstract}
A new model to predict the onset of significant void (OSV) in transient subcooled flow boiling has been developed. The model is based upon the influence on vapor bubble departure of the single-phase temperature profile. The steady-state result of the present model was compared to the experimental data of Whittle and Forgan [1] and Dougberty, et al. [2], showing an excellent agreement. The model was then employed in a transient analysis of OSV for vertical downwards turbulent flow to predict whether OSV takes place. The condition for OSV to occur in transient How situations was also predicted by this model. Two modes for pressure gradient change inside the channel are considered in the present study: step change and ramp change. The calculations were made for various combinations of the flow operating condition and the mode of pressure drop change.
\end{abstract}

KEYWORDS: Onset of Significant Void, Bubble Departure, Transient Subcooled Boiling, Vertical, Parallel Plates, 


\section{INTRODUCTION}

In a particular reference lose of flow accident, the flow through the channels decreases rapidly, owing to the decrease in the pressure difference acrose the channels resulting from the pipe break. The power also decreases, following the reactor trip. There is thus a race between the decreases in flowrate and power which determines the conditions within the channels, and ultimately the temperature of the fuel elements. Normally, the flow is all-liquid, but as the flow decreases, it is possible to have the onset of nucleate boiling (ONB). This corresponds to the appearance of the first butbles on the walls. Since the bulk of ihe liquid at the point of appearance is subcooled, the bubbles usually do not immediately detach from the wall. As the flow decreases further, the point of ONB moves backwards alnng the wall surface, resulting in a formation of a bubble boundary layer in the vicinity of the wall. The appearance of the bubble boundary layer causes the pressure gradient to increase, owing to the increased apparent roughness of the wall. At some point, owing to the detachment of the individual bubbles or the instability of the bubble boundary layer, there is significant vapor generation and mixing of bubbles with the core liquid. This onset of significant void (OSV) generally signals the onset of flow instability (OFI) in a system with pressure-driven boundary conditions. This is because the sudden decrease in mean flow density results in an increased pressure gradient due to the combined effects of friction and acceleration. With pressure boundary conditions, rather than specified inlet flowrates, this can lead rapidly to OFI, and consequent dryout and overheating.

Current methods of predicting the onset of significant void, and of the subsequent flow instability, are based on steady-state, small-scale experiments on forced-convection, subcooled nucleate boiling (FCSNB). This is appropriate, since no experimental studies have come to our attention involving transient FCSNB. The current method of choice is to use the empirical correlation of Saha and Zuber [3], together with a calculation for the velocity and temperature of the bulk liquid as functions of position and time throughout the transient. However, a more mechanistic approach is needed in predicting OFI for the transient case, since the time of the transient is comparable to the residence time of a fuid particle in the channel, and also to the time delays 
for the development of the thermal and velocity boundary layers at the wall.

The objective of the present study is to develop a mechanistic model for OSV and also to establish a criterion for OSV under transient Gow conditions. Towards these sims, the hydrodynamic condition for the departure of an isolated vapor bubble in a vertical downwards flow between parallel plates was established from a force balance acting around the bubble. Then a transient analysis of the two-dimensional momentum and energy equations was carried out to obtain transient temperature profiles when the pressure gradient and the heat flux are timedependent. Following the criterion suggested by Levy [4] and other investigators [5-7], the onset of significant void in transient vertical tow boiling was predicted. In addition, the present theory was compared with the Saha-Zuber correlation [3], which has been widely used in computer codes for nuclear safety analysis. 


\section{DESCRIPTION OF A MECHANISTIC MODEL FOR OSV}

The present model aims at predicting the OSV heat flux in transient vertical downwards flow between parallel plates, provided that the operating pressure, the pressure drop and the liquid inlet temperature are prescribed. The basic concept of the present model is similar to that of previous models proposed by such investigators as Levy [4], Staub [5] and Rogers, et al. [6]. However, the present model is based upon a full two-dimensional analysis of fluid flow and beat transfer, whereas the previous models employed a one-dimensional beat tracisfer equation, although the temperature distribution obtained by Martinelli [8] was used to evaluate the liquid temperature at the top of the bubble.

Experimental evidence shows that the onset of significant void (OSV) precedes and is very close to OFI $[2,9]$. Furthermore, the OSV phenomenon is characterized by the departure of vapor bubbles from the heated surface. Thus, in the present model, attention is focused on the thermal and hydrodynamic conditions under which a bubble starts to leave the surface to predict OSV.

Two requirements are considered in the present model to establish the criterion for the depar. ture of an isolated bubble. One is that the resultant of the forces tending to detach the bubble from the surface exceeds the resultant of the forces bolding it on the surface at bubble departure. The other is a thermal condition, which states that the lemperature at the top of the bubble should be at least equal to the saturation temperature for bubble departure.

The basic concept of the present model is described in detail elsewhere[10].

\subsection{Hydrodynamic Condition of bubble departure}

Consider a vapor bubble attached to the vertical wall in forced-convection for boiling. The bubble is ascumed to be a sphere. Following Levy [2] and other investigators [5-7], it is assumed that the forces parallel to the surface are critical in determining the condition of bubble departure. Thus only three major forces will be considered bere. These are the drag force, the surface tension force, and the buoyancy force.

Based upon the force balance around the bubble, the condition for the bubble detachment 
can be written as follows:

$$
F_{D}-F_{B}-F_{S} \geq 0
$$

where the drag force, $F_{D}$, is the component acting to detach the bubble, while the buoyancy force, $F_{B}$, and the surface tension force, $F_{S}$, are the components tending to hold it on the surface. The buoyancy force is given by:

$$
F_{B}=C_{B}\left(\rho \rho-\rho_{\rho}\right) g\left(\frac{4}{3} \pi R_{b}^{3}\right)
$$

where $C_{B}$ is a proportionality constant and may be determined empirically. Similarly, the surface tension force, $F_{S}$, can be expressed as follows:

$$
F_{S}=C_{s} \sigma\left(2 \pi R_{b}\right)
$$

where $C_{S}$ in a proportionality constant. The drag force is proportional to the projected area of the bubble and the dynamic pressure of the liquid fow, and thus can be written as:

$$
F_{D}=C_{D}\left(\frac{1}{2} \rho \rho u_{m}^{2}\right)\left(\pi R_{b}^{2}\right)
$$

Subotituting Equations (2), (3), and (4) into Equation (1) and converting it into dimensionless form, one obtains:

$$
K_{1}\left(R_{i}^{*}\right)^{2}-R_{i}^{i}+K_{2} \leq 0
$$

where the dimensionleas bubble radius, $R_{i}^{\circ}$, and the dimensionlese parameters, $K_{1}$ and $K_{2}$, are given by:

$$
\begin{gathered}
R_{t}^{\circ}=\frac{R_{b}}{H} \\
K_{1}=\frac{8}{3}\left(\frac{C_{B}}{C_{D}}\right)\left(\frac{\left(\rho_{\rho}-\rho_{\rho}\right) g H}{\rho \rho u_{m}^{2}}\right) \\
K_{2}=\left(\frac{C_{s}}{C_{D}}\right)\left(\frac{4 \sigma}{\rho \rho u_{m}^{2} H}\right)
\end{gathered}
$$

Thus, if $4 K_{1} K_{2}<1$, the dimensionless bubble radius when the bubble starts to depart from the beated wall can be approximated as followa:

$$
R_{i}^{*}=\frac{R_{t}}{H} \simeq K_{2}
$$


Thus, the dimensionless bubble diameter at the bubble departure is inversely proportional to the Weber number:

$$
\frac{D_{\mathrm{b}}}{H}=\left(\frac{C_{s}}{C_{D}}\right)\left(\frac{8 \sigma}{\rho, u_{m}^{2} H}\right)
$$

The evaluation of the coeficients, $\widetilde{V}_{S}$ and $C_{D}$, in Equation (10) was made in a previous paper [10]. As mentioned in the earlier paper, the drag coefficient, $C_{D}$, is due to Avdeev [11]:

$$
C_{D}=\left[5.84+16.0 \log \left(0.93+0.065 K^{0.25}\right)\right]^{-2}
$$

where the dimensionless parameter, $K$, is defined by:

$$
K=\frac{\rho f u_{m} C_{p f}(2 H)\left(T_{\text {oet }}-T_{f}\right)}{k_{f}\left(T_{w}-T_{\text {oet }}\right)}
$$

The surface tension coefficient, $C_{S}$, wa proposed in the previous paper [10] as follows:

$$
C_{s}=0.00048\left[u_{m} /\left(g \sigma / \rho_{\rho}\right)^{1 / 4}\right]^{1.28}
$$

where the reference velocity was taken as $\left(g \sigma / \rho_{f}\right)^{1 / 4}$ which bas emerged from the condition that $4 K_{1} K_{2}<1$.

Physically, the condition of $4 K_{1} K_{2}<1$ means that the buoyancy force is negligibly small compared to the surface tension and the drag forces. The experimental evidence of Whittle and Forgan [1], that the flow direction in vertical channel, whether up-fow or down-tow, is not important for the initiation of the onset of flow instability, also confirm the negligibility of the buoyancy force. This reault agreee with the argument of Levy [4] that the buoyancy force exerted on the vapor bubble in negligible in forced-convection boiling flow.

\subsection{Transient Analysis of Temperature Profile}

Consider a vertical downwarde turbulent fiow between heated parallel plates. The channel length is $L$ and the channel depth is $2 H$. Initially, the flow bas a fully-developed velocity profile corresponding to a specified constant pressure gradient, which is a solution of Equation (14) when the inertis term vanishes. The initial temperature profile is also a solution of the steady-state energy equation corresponding to a specified constant heat-flux boundary condition. When $t>0$, 
a new presoure gradient and a new heat fux, both of which are in general time-dependent, are imposed a boundary conditions. The momentum equation of the flow can be written as follows:

$$
\frac{\partial u(y, t)}{\partial t}=-\frac{1}{\rho_{j}} \frac{d p}{d x}(t)+\frac{\partial}{\partial y}\left[\left(\nu+\epsilon_{M}\right) \frac{\partial u(y, t)}{\partial y}\right]
$$

with the boundary conditions:

$u=0$ at $y=0 ; \frac{\partial u}{b y}=0$ at $y=H$

and the initial condition:

$u=u_{0}(y)$ when $t=0$

where the pressure term includes the hydrostatic pressure as well as the static pressure. The energy equation may be written as:

$$
\frac{\partial T(x, y, t)}{\partial t}+u(y, t) \frac{\partial T(x, y, t)}{\partial x}=\frac{\partial}{\partial y}\left[\left(\alpha+c_{H}\right) \frac{\partial T(x, y, t)}{\partial y}\right]
$$

with the boundary conditions:

$-k \frac{\partial T}{\partial y}=q(t)$ at $y=0 ; \frac{\partial T}{\partial y}=0$ at $y=H ; T=T_{i}$ at $z=0$

and the initial condition:

$T=T_{0}(x, y)$ when $t=0$

In Equations (14) and (15) $C_{M}$ and $C_{H}$ denote the eddy viscosity and the eddy thermal diffusivity, respectively. Several models for the eddy viscosity have been proposed in the past. A modified Reichardt model suggested by Wilson and Medwell [12] is used in the present study. The original model for the eddy viscosity proposed by Reichardt [13] in valid only for regions away from the wall. Bowever, the wall effect was taken into account by multiplying by the van Driest damping factor [14] in thie modified model:

$$
\mathrm{CH}_{\mathrm{N}}=0.133 H \mathrm{u}^{*}\left[0.5+\left(\frac{H-y}{H}\right)^{2}\right]\left[1.0-\left(\frac{H-y}{H}\right)^{2}\right]\left[1.0-\exp \left(-\frac{y}{A}\right)\right]
$$

where $u^{*}$ in the friction velocity and $A$ is defined by:

$$
A=A^{+}\left(\frac{v}{u^{2}}\right)
$$

In Equation (17), $A^{+}$is the damping constant and is taken to be 40 , following Kawamura [15]. For the eddy thermal diffusivity, White [16] have recommended that the turbulent Prandtl number 
be taken a constant.

$$
P_{r_{1}}=\frac{C M}{C H} \simeq 0.9
$$

The governing equations are converted into dimensionless form using the following dimensionless variables:

$$
\begin{gathered}
U=\frac{u}{u_{m \bullet}} \\
X=\frac{x}{L} \\
Y=\frac{y}{H} \\
T=\frac{t}{\left(H^{2} / \nu_{0}\right)} \\
P=\frac{p}{\frac{1}{2} \rho \rho u_{m 0}^{2}} \\
\theta=\frac{T-T_{i}}{T_{i o s}-T_{i}}
\end{gathered}
$$

where $u_{m_{0}}$ in the initial mean velocity.

The dimensionless momentum equation becomes:

$$
\frac{\partial U}{\partial r}=-\frac{u_{m_{0}} H^{2}}{2 \nu_{0} L}\left(\frac{\partial P}{\partial X}\right)+\left(\frac{\nu}{\nu_{0}}+\epsilon_{M}^{+}\right) \frac{\partial^{2} U}{\partial Y^{2}}+\left[\frac{\partial}{\partial Y}\left(\frac{\nu}{\nu_{0}}+\epsilon_{M}^{+}\right)\right] \frac{\partial U}{\partial Y}
$$

mith the dimensionless boundary conditions:

$U=0$ at $Y=0 ; \frac{\partial U}{\partial Y}=0$ at $Y=1$

and the dimensionlese initial condition:

$U=U_{.}(Y)$ when $r=0$

In Equation (25), the dimensionless eddy viscosity, $C_{M}^{+}$, in defined by:

$$
c_{M}^{+}=\frac{C_{M}}{\nu_{0}}
$$

Similarily, the dimensionleas energy equation can be written as:

$$
\frac{\partial \theta}{\partial \tau}+R e_{0}\left(\frac{H}{4 L}\right) U \frac{\partial \theta}{\partial X}=\frac{1}{P r_{0}}\left[\left(\frac{\alpha}{\alpha_{0}}+\epsilon_{H}^{+}\right) \frac{\partial^{2} \theta}{\partial Y^{2}}+\frac{\partial}{\partial Y}\left(\frac{\alpha}{\alpha_{0}}+\epsilon_{t}^{+}\right)\left(\frac{\partial \theta}{\partial Y}\right)\right]
$$

with the dimensionless boundary conditions:

$-\frac{\partial \varphi}{\partial Y}=q^{\circ}$ at $Y=0 ; \frac{\partial \theta}{\partial P}=0$ at $Y=1 ; \theta=0$ at $X=0$ 
and the dimensionless initial condition:

$\theta=\theta_{\text {, when }} r=0$

where $q^{\bullet}$ and $\theta_{0}$ are defined by, respectively:

$$
\begin{gathered}
q^{\bullet}=\frac{q}{\left(k_{J} / H\right)\left(T_{0 \text { ot }}-T_{i}\right)} \\
\theta_{0}=\frac{T_{0}-T_{i}}{T_{\text {oet }}-T_{i}}
\end{gathered}
$$

In Equatica (27), the dimensionless eddy thermal diffusivity, the Reynolds number and the Prandtl number are defined as, respectively:

$$
\begin{gathered}
\epsilon_{H}^{+}=\frac{\epsilon_{H}}{\alpha_{0}}=\frac{1}{0.8} \operatorname{Pr}_{0} \epsilon_{N}^{+} \\
R e_{0}=\frac{4 H u_{m_{0}}}{\nu_{0}} \\
\operatorname{Pr}_{0}=\frac{\nu_{0}}{\alpha_{0}}
\end{gathered}
$$

The solution of the dimensionless momentum and energy equations will be obtained using a finite difference method. Both equations are put into a finite difference form using the CrankNicolson method. Central differences in the $Y$ direction and backward differences in the $X$ direction are employed for the convective term of Equation (27).

A stretching node technique is employed to reduce the number of nodes in $Y$ direction. This can be written as follow:

$$
Y_{i+1}-Y_{i}=k_{n}\left(Y_{i}-Y_{i-1}\right)
$$

where the stretching coefficient, $k_{n}$, is generally taken to be between 1.07 and 1.10. This stretching technique greatly reduces the number of nodes without loning accuracy of the solution, in particular, in the viscows sublayer. The firat node for the momentum equation is taken at the fluid in the vicinity of the solid surface, wheress it is taken on the solid wall for the energy equation.

The change of the fluid properties as a function of time is taken into consideration by evat uating them at the mean of the bulk liquid inlet and outlet lemperature at each previous time 
step. It is thought that the error due to evaluating the fluid properties in this manner is not significant.

\subsection{Prediction of OSV in transient flow}

For vertical downwards turbulent tow between beated parallel plates, the liquid has initially a fully-developed velocity profile, $u_{0}(y)$, corresponding to an initial pressure gradient and a temperature profile, $T_{0}(x, y)$, resulting from an initial beat fux. When $t>0$, a new pressure gradient is imposed inside the channel, resulting in a decrease of the liquid mean velocity. It can be a step change, or a time-dependent change, as a ramp change. The heat flux is assumed to be kept constant. Due to the decrease of the mean velocity, the liquid mean temperature will rise. It is of concern to predict whether OSV will take place before a new steady-state will be attained under specific geometrical and operating conditions. Because OSV take place first at the bottom of the channel, where the fuid mean temperature is aways maximum, atteation is focused on the local condition at the bottom for OSV.

The transient dimensionless velocity and temperature profiles are calculated from Equations (25) and (27). The bubble diameter when the bubble starts to depart from the beated wall is calculated from Equation (10). The use of Equation (10) in the transient analysis may be posoible if it is assumed that the maximum bubble diameter changes slowly during the transient flow compared to the bubble lifetime. In calculating the bubble diameter, the guid properties evaluated at the local liquid mean temperature should be used. The diatance from the wall at which the saturation temperature is reached is determined from the transient liquid temperature profile at the bottom of the channel. At each time step, the magnitude of the bubble diameter is compared to that of the diatance to the point of the saturation temperature. When the temperature at the top of the bubble reaches the saturation temperature, OSV is thought to occur. If the distance to the saturation temperature in always smaler than the bubble diameter at each time step until a new steady-state is attained, one may consider that OSV will never take place under that particular condition. 


\section{COMPARISON}

Comparisons of the present theory with the available dats and other model were discussed in detail in the previous paper [10]. Only steady-state dats are available at the present time and thus was compared with the steady-state result of the present model. The steady-state result was obtained by solving the liquid temperature profiles from the steady-state momentum and energy equations together with the hydrodynamic condition of bubble departure, that is, Equation (10). The results of comparison of the present theory with the data of Whittle and Forgan [1] and the data of Dougherty, et al.[2] showed, in the previous paper [10], that the present theory is in excellent agreement with both data sets. Most data were within error bounds of $\pm 10 \%$.

In addition, a comparison of the present theory was made with the empirical correlation suggested by Saha and Zuber [3]. The Saba-Zuber correlation is very simple and convenient, and bas been widely used in computer codes for nuclear safety analysis. However, recent experiments [2,9] indicate that the discrepancy between the data and the correlation appears to be considerable, with data scatter beyond the error margins described by Saba and Zuber [3] originally. The comparison was done by plotting the numerical data calculated from the present theory in the $(P e, S t)$ plane. It was indicated that the present numerical data are fairly well fitted with the correlation [10]. However, the present theory hinted that, contrary to the correlation, the Stanton number is not solely related to the Peclet number, showing multiple values of the Stanton number depending upon the geometrical size at a single value of the Peclet number. The result may explain the large error margins in the Saha-Zuber correlation, and also the scatter beyond the specified error margin. More details in comparison can be found in [10]. 


\section{COMPUTATIONAL RESULTS}

Numerical calculations for predicting the transient OSV in vertical downwards flow between parallel plates were made for the following dimensiona:

channel height: $0.00685(\mathrm{~m})$

channel length: $3.8(m)$

inlet temperature: $25\left({ }^{\circ} \mathrm{C}\right)$

saturation temperature: $125\left({ }^{\circ} \mathrm{C}\right)$

pressure gradient: step or ramp change from 55.0 to $24.0(k \mathrm{~Pa} / \mathrm{m})$

The dimensions were obtained from actual operating conditions.

4.1 Typical velocity and temperature calculations

The mean velocity and the exit bulk temperature when the heat flux is kept at a constant value $\left(q=2.0 \mathrm{MW} / \mathrm{m}^{2}\right)$ are shown in Figures 1 and 2 , respectively. The 1-D calculation results are also shown in the figures. The 1-D model is described in the Appendix. It is seen that a new steady-state is attained after some time. The differences between 1-D and 2-D models seem to be lese than $5 \%$ for esch parameter. It turns out that the energy equation itself for the 1-D and 2-D models gives almoet no difference. Thus, the difference between 1-D and 2-D models in Figure 2 is attributable to the mean velocity difference shown in Figure 1.

Figures 3 and 4 show typical velocity and temperature profiles at the outlet during transient change of tion.

\subsection{Prediction of transient OSV at constant beat flux}

Predictions of OSV in transient alow have been made for various operating conditions. Figures 5 and 6 show the mean velocity and the exit bulk temperature as a function of time for several heat fluxes ater a step change of pressure gradient. The geometric and operating conditions are before. At $t=0$, a step change of pressure gradient from 55 to $24(k P a / m)$ was made, while the heat fux was maintained at a constant value. The mean velocity decreases, and the bulk temperature increases. Figure 5 shows slight changes of the velocity variation depending on the magnitude of the heat flux added from both plates. It is shown in Figure 6 that OFI 
will always take place for heat fluxes greater than $2.2\left(\mathrm{MW} / \mathrm{m}^{2}\right)$. Accoiding to the steady-state calculation, the OSV heat flux for initial pressure gradient, $55(\mathrm{kPa} / \mathrm{m})$ will be $3.34\left(\mathrm{MW} / \mathrm{m}^{2}\right)$. Thus, this value can be regarded as the maximum possible heat flux to avoid OSV under steadystate operating conditions. Figure 7 indicates the transient effect of the OSV numerical data for various beat fluxes. This could be obtained by comparing the transient OSV heat fux with the steady-state OSV heat flux with the same mean velocity as that for the transient case. In the figure, the difference between the transient and steady-state heat fluxes represents the transient term in Equation (15). Thus, at initial and final states, the transient effect will be insignificant as shown in Figure 7. The maximum ratio of the heat flux contributed to the transient term to the total beat fux would be approximately $15 \%$. This ratio should be compensated when steady-state correlations of OSV are used in predicting OSV in transient flow and beat transfer.

Typical transient OSV predictions for ramp changes in pressure gradient are shown in Figures 8-11. The resulte were obtained for a constant heat lux of 3.0 and $2.4\left(\mathrm{MW} / \mathrm{m}^{2}\right)$ with six different ramp times. In the figure, $t_{r}=0.0$ corresponds to a step change.

It is interesting to note that the outlet subcooling appears to be almost identical regardless of the mode of pressure gradient change and the heat flux. This observation is not in conflict with the finding that the local Stanton number slightly decreases as the Peclet number increases, as mentioned in the previous paper [10]. As seen in the result of the previous paper [10], the outlet subcooling is relatively insensitive for the high velocity range when OSV takes place. For the particular transient flow dealt with here, the mean velocity at which OSV occura lies between only $7(\mathrm{~m} / \mathrm{s})$ and $9(\mathrm{~m} / \mathrm{s})$. As will be seen later, the Stanton number is a wesk function of the Peclet number in this range of mean velocity.

\subsection{Simple OSV equation applicable to 1-D computer code}

The present theory is based upon a two-dimensional flow and beat transfer analyois. There may be difficulty in its application to computer codes for nuclear safety analysis, which are, in general, based upon one-dimengional flow and heat transfer analysis. Here a single simple equation is suggested to give a criterion for OSV in transient flow under the present geometric 
and operating conditions. The Stanton number calculaled for tranaient OSV in the present study can be approximated by the following equation:

$$
S t=0.076 P e^{-0.2}
$$

This equation predicte lower Stanton numbers compared to the Saha-Zuber correlation for Peclet numbers between 500,000 and 900,000 , as shown in Figure 12. Thus, the present theory is more conservative than the Saha-Zuber correlation. 


\section{DISCUSSION AND CONCLUSIONS}

The present theory was derived under the assumption that the buoyancy force is negligibly small. This condition leads to a criterion for a lower limit of the mean velocity for the present theory. This can be calculated from the condition that $4 K_{1} K_{2}<1$. Using Equations (7) and (8), one obtains:

$$
u_{m}>\left[\frac{128}{3} \frac{C_{B}}{C_{D}} \frac{C_{S}}{C_{D}} \frac{\left(\rho_{\rho}-\rho_{e}\right)}{\rho_{\rho}} \frac{g \sigma}{\rho_{\rho}}\right)^{1 / 4}
$$

Thus, it will be approximately $0.71(\mathrm{~m} / \mathrm{s})$ at an operating pressure of $0.1(\mathrm{MPa})$ assuming that $C_{B} / C_{D}$ is $O(1)$ and $C_{S} / C_{D}$ is $O(1)$, when $4 K_{1} K_{2} \approx 0.1$. For the velocity range smaller than this lower limit, the evaluation of $C_{B}$ should be made before the present theory is applied. No physical evaluation can be found on the value of $C_{B}$ in the literature. However, it is expected to be $O(1)$.

It is interesting to note in Figure 12 that the present theory predicts that $S t \propto P e^{-0.20}$. This means that, from the definition of the Stanton number, $N u \propto R e^{0.00}$, considering the beat transfer from the bubble boundary to the liquid core. This result is exactly identical to the Dittus-Boelter equation for the beat transfer coefficient in single-phase flow.

The fact that the transient calculations all show the onset of significant void, and hence of flow instability, at the same exit bulk temperature for various power levels is rather remarkable. One physical interpretation is that the departure of bubbles from the wall is condensation-controlled. With highly-subcooled bulk liquid bubbles grom and collapse at the wall. As the bulk liquid warms up, the collapee time becomes considerably longer than the growth time, because the thermal boundary layer around the bubble thickens during the collapse phase. At some point the collapee becomes very slow, and the bubble remains close to ito maximum radius for a relatively long time, which allowe the lif forces to detach it from the wall.

As shown in Figure 12 the fact that che Stanton number, as defined by Saha and Zuber [3], remains nearly constant is not in contradiction with the observation concerning the steady-state result mentioned in the previous paper [10]. With the specific step pressure change, the bulk velocity changes from about $9(\mathrm{~m} / \mathrm{s})$ to only about $7(\mathrm{~m} / \mathrm{s})$ for OSV, while the wall heat flux 
remains constant. If the bulk liquid subcooling is also constant at OSV, the Stanton number, $S t=: / G C_{p}\left(T_{\text {oet }}-T_{d}\right)$, abo is approximately constant at this bigh end of the Peclet number range. However, at lower Peclet numbers, the variation in the Stanton number is very much marked.

This is still a highly empirical model, although it contains much more physica than previous models. More experimental information over a wide range, particulasly with fow and bubble visualization, is needed to check the details of this model, and to make necessary modifications. Neverthelese, it is encouraging that such a wide range of data can, at the present time, be fitted closely with the choice of a single empirical parameter. 


\section{ACKNOWLEDGMENT}

This work was supported by Westinghouse Savannah River Company. We thank the project monitor, B. S. Johnston for helpful comments. S. C. Lee received partial support from the Ministry of Education, Republic of Kores. 


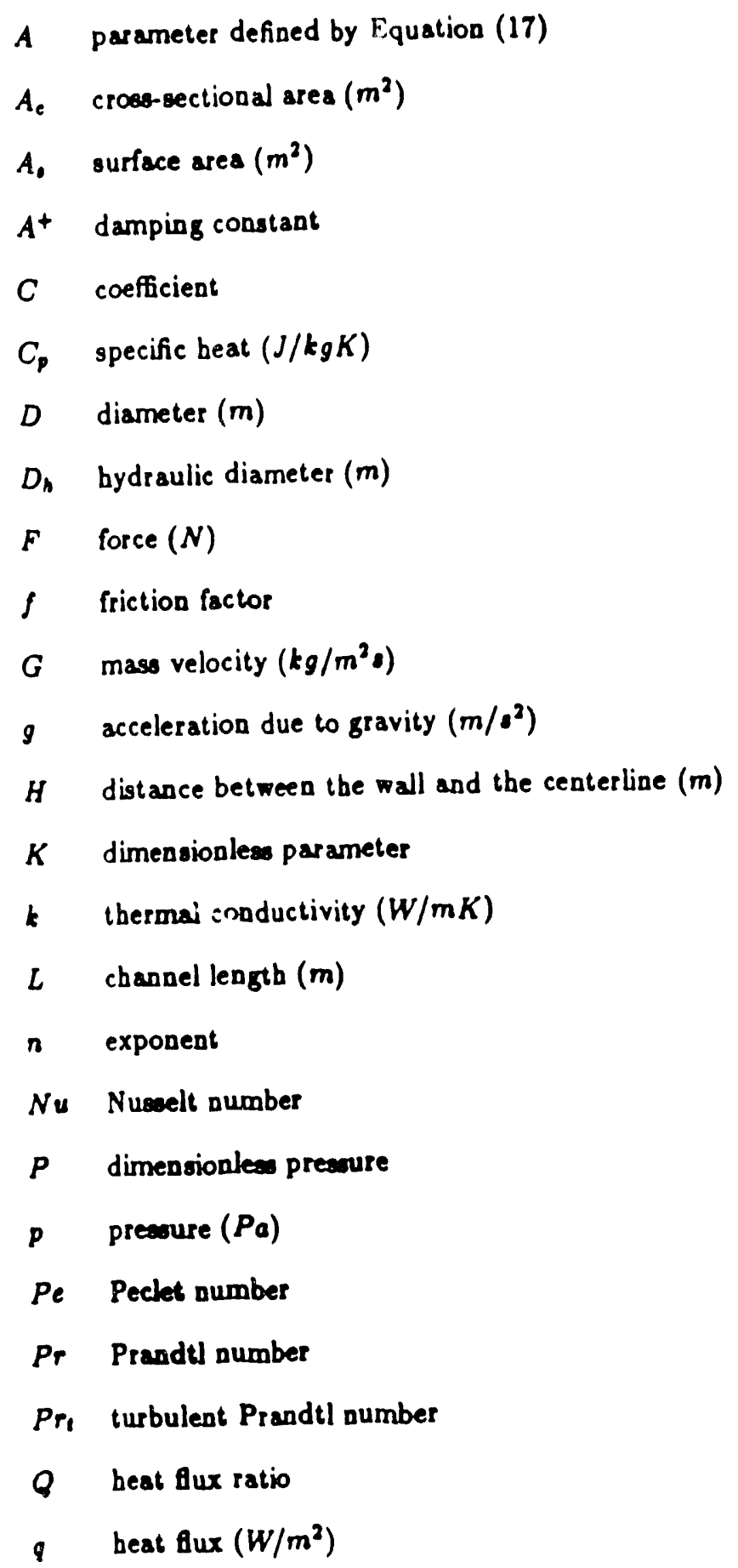




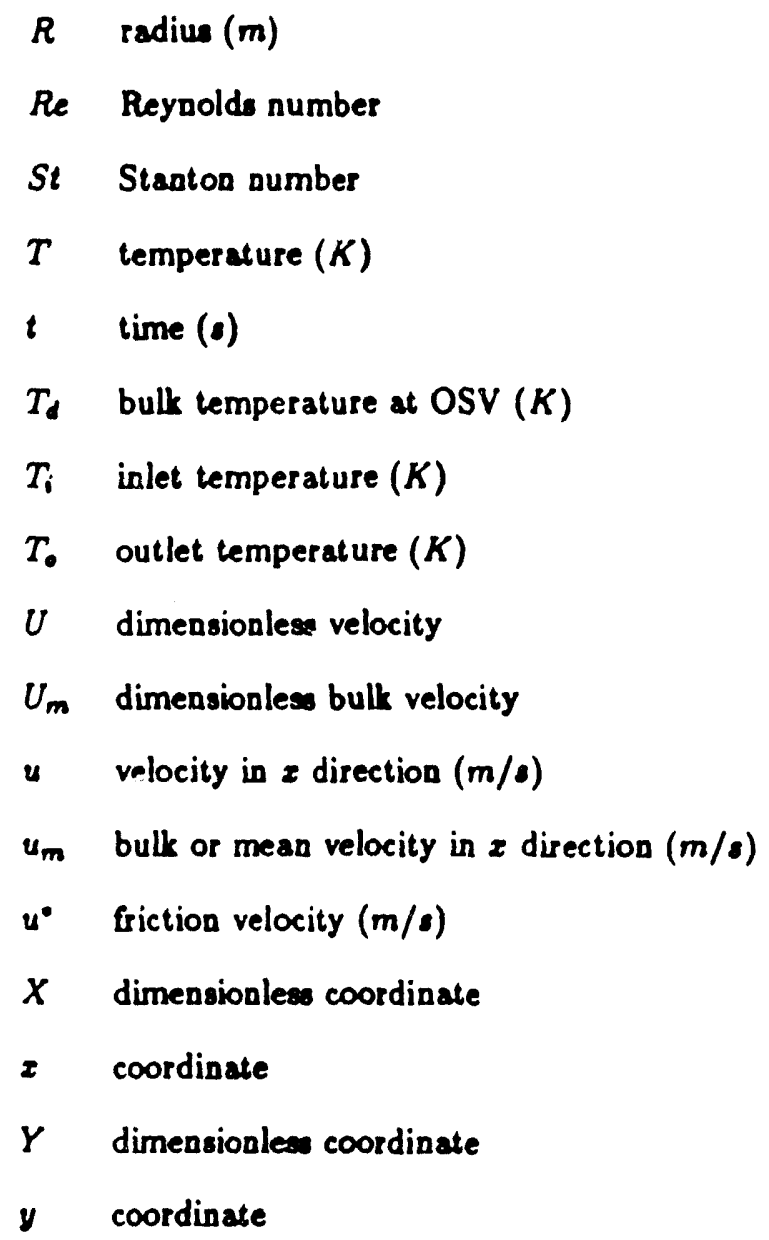

\section{Greek Symbols}

a thermal diffuaivity $\left(\mathrm{m}^{2} / \mathrm{e}\right)$

$\epsilon_{H}$ eddy thermal diffurivity $\left(\mathrm{m}^{2} / \mathrm{o}\right)$

$C_{M}$ eddy vincosity $\left(\mathrm{m}^{2} / 0\right)$

- dimensionlese temperature

$\nu \quad k i n e m a t i c$ viscoaity $\left(\mathrm{m}^{2} / \mathrm{s}\right)$

$\rho$ density $\left(\mathrm{kg} / \mathrm{m}^{3}\right)$

$\sigma$ surface tension $(N / m)$ 
$r$ shear stress or dimensionless time

\section{Subscript}

$B$ buoyancy

6 bubble

$D$ dres

$f$ liquid

g ga

i i-th node in Y-direction

- initial state

$S$ surface tension

sat seturation

$w$ wall

\section{Superscript}

- dimensionles

+ dimensionleas 


\section{REFERENCES}

[1] R.H. Whittle and R. Forgan, Correlation for the minima in the presaure drop versus tow-rate curves for aubcooled water fowing in nasrow beated channels, Nuclear Engineering and Design 6 (1967) 89-99.

[2] T. Dougherty, C. Fighetti, G. Reddt, B. Yang, T. Jafri, E. McAssey and Z. Qureshi, Flow boiling in vertical down-tow, Proceedings of 10th Int. Beat Transfer Conf. 6 (1990) 9-14.

[3] P. Sahs and N. Zuber, Point of net vapor generation and vapor void fraction in subcooled boiling, Proceedings of Fifth International Heat Transfer Conference 4 (1974) 175-179.

[4] S. Levy, Forced convection subcooled boiling: prediction of vapor volumetric fraction, Int. J. Heat Mass Transfer 10 (1967) 951-965.

[5] F.W. Staub, The void fraction in subcooled boiling: prediction of the initial point of net vapor generation. J. Heat Transfer 90 (1968) 151-157.

[6] J.T. Rogers, M. Salcudean, Z. Abdullah, D. Mcleod and D. Poirier, The onset of significant void in up-fiow boiling of water at bow pressure and velocities, Int. J. Heat Mass Transfer 30 (1987) 2247-2260.

[7] R.B.S. Winterton, Flow boiling: prediction of bubble departure, Int. J. Heat Mas Transfer 27 (1984) 1422-1424.

[8] R.C. Martinelli, Heat transfer to molten metals, Trans. ASME 6 (1947) 941-947.

[9] B.S. Johnoton, Subcooled boiling of downward flow in a vertical annulus, Savannah River Laboratory, DPST-88-891 (1988).

[10] S.C. Lee and S.G. Bankof, Theoretical prediction of the oneet of flow instability in vertical fow between paralled plate, to be presented in National Beat Tranafer Conf., San Diego, CA (Auguat 1992).

(11) A.A. Avdeev, Application of the Reynolds analogy to the investigation of surface boiling in conditions of forced motion, High Temperature 24 (1986) 100-108. 
[12] N.W. Wilson and J.O. Medwell, An analysis of the developing turbulent bydrodynamic and thermal boundasy layers in an internally heated annulus, J. Beat Transfer 93 (1971) 25-32.

(13) B. Reichardt, Vollstandige darstellung der turbulenten geschwindigkeitsverteilung in glatten leitungen, Z. Anger. Math. Mech. 31 (1951) 208.

[14] E.R. van Driest, On turbulent flow near a wall, Beat Transfer and Fluid Mechanics Institute Symposium, Paper No. 12, University of California, Los Angeles, CA (1955).

[15] H. Kawamura, Experimental and analytical study of transient beat transfer for turbulent flow in a circular tube, Int. J. Heat Mass Transfer 20 (1977) 443-450.

[16] F.M. White, Heat and Mass Transfer (Addison-Wesley, Massachusetts,1988) pp. 315-332. 


\section{APPENDIX: ONE-DIMENSIONAL FLOW AND BEAT TRANSFER ANALYSIS}

The momentum equation for unsteady one-dimensional tow can be written as follows:

$$
\rho \frac{d u_{m}}{d t}=\frac{d p}{d x}(t)-\frac{T_{w}}{H}
$$

and the initial condition becomes:

$u_{m}=u_{m e}$ when $t=0$

In the equation, the wall shear stress, $\tau_{w}$, can be defined by:

$$
\tau_{w}=\frac{1}{8} \rho \rho u_{m}^{2}
$$

and the friction factor will be given by:

$$
f=C R^{n}
$$

where $C=0.3164$ and $n=-0.25$ are given for the Blasius equation and $C=0.1840$ and $n=-0.20$ for the White equation [16].

The energy equation can be written as follows:

$$
\rho C_{p}\left[\frac{\partial T}{\partial t}+u_{m}(t) \frac{\partial T}{\partial x}\right)=\frac{q(t)}{H}
$$

The boundary condition is

$T=T_{i}$ at $x=0$

and the initial condition becomea:

$T=T_{0}(x)$ when $t=0$

The governing equations will be converted into dimensionlese form using the following dimensionlese variables:

$$
\begin{gathered}
U_{m}=\frac{u_{m}}{u_{m \bullet}} \\
X=\frac{x}{L} \\
\tau=\frac{t}{\left(H^{2} / \nu_{0}\right)} \\
P=\frac{P}{\frac{1}{2} p_{\rho} u_{m \bullet}^{2}}
\end{gathered}
$$




$$
\theta=\frac{T-T_{i}}{T_{\text {ot }}-T_{i}}
$$

Then, the dimensionless momentum equation becomes:

$$
\frac{d U_{m}}{d \tau}+\frac{C}{32}\left(\frac{\nu}{\nu_{0}}\right)^{-n} R e_{0}^{n+1} U_{m}^{2+n}=-\left(\frac{H}{8 L}\right) R e_{0}\left(\frac{d P}{d x}\right)
$$

where the Reynolds number at the initial state, Re, is defined by:

$$
R e_{0}=\frac{4 H u_{m e}}{\nu_{0}}
$$

and the dimensionless initial condition:

$U_{m}=1$ when $r=0$

The dimensionless energy equation can be expressed by:

$$
\frac{\partial \theta}{\partial \tau}+\left(\frac{H}{4 L}\right) R_{0} U_{m}(\tau) \frac{\partial \theta}{\partial X}=\frac{1}{4} R_{e} S t_{0} Q(r)
$$

where the Stanton number at the initial state, $S t_{0}$, is defined by:

$$
S t_{0}=\frac{q_{0}}{G_{0} C_{p}\left(T_{101}-T_{i}\right)}
$$

and the heat fux ratio, $Q$, is:

$$
Q(\tau)=\frac{q(t)}{q_{0}}
$$

Both dimensionless equations can be solved numerically. 


\section{LIST OF FIGURES}

Figure 1. Comparison between the mean velocities of 1-D and 2-D models.

Figure 2. Comparison between the exit bulk lemperatures of 1-D and 2-D models.

Figure 3. Typical velocity profiles as a function of time.

Figure 4. Typical exit temperature profiles as a function of time.

Figure 5. Mean velocity variations for various heat fluxes with a step change of pressure gradient. OSV reached at end of each initial heat flux curve.

Figure 6. Exit bulk temperature variations for various heat fluxes with a step change of pressure gradient.

Figure 7. Comparison between steady-stale and transient beat Guxes.

Figure 8. Mean velocity variations for various ramp times $\left(q=3.0 \mathrm{MW} / \mathrm{m}^{2}\right)$.

Figure 9. Exit bulk temperature variations for various ramp times $\left(q=3.0 \mathrm{MW} / \mathrm{m}^{2}\right)$.

Figure 10. Mean velocity variations for various ramp times $\left(q=2.4 \mathrm{MW} / \mathrm{m}^{2}\right)$.

Figure 11. Exit bulk temperature variations for various ramp times $\left(q=2.4 \mathrm{MW} / \mathrm{m}^{2}\right)$.

Figure 12. Comparison of numerical transient data with Equation (35). 
Fig. 1. Comparison between the mean velocity of $1-D$ and $2-D$ models.

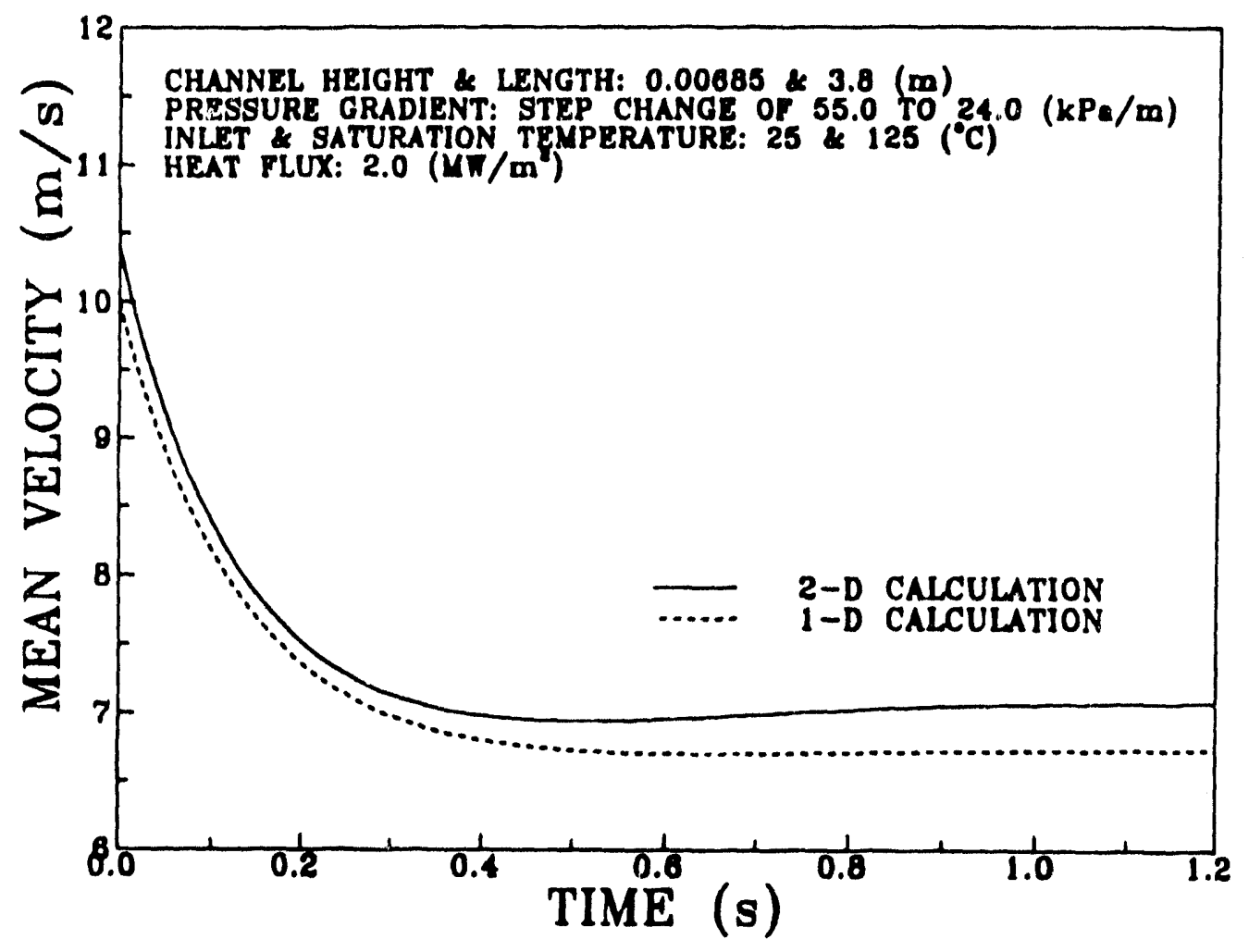


Fig. 2. Comparimon between the exit bulk lemperature of $1-D$ and 2-D models.

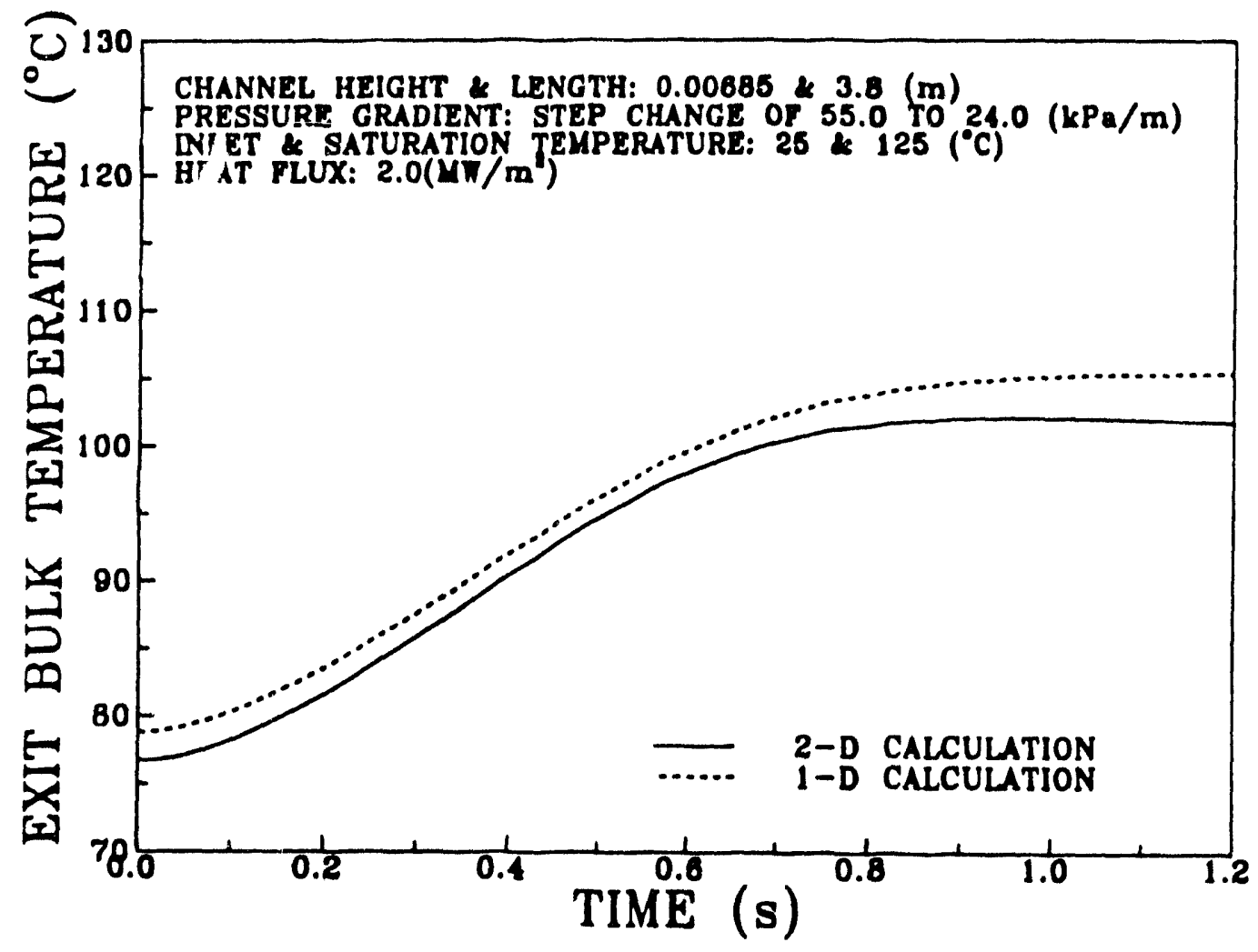


Fig. 3. Typical velocity profiles as anction of lime.

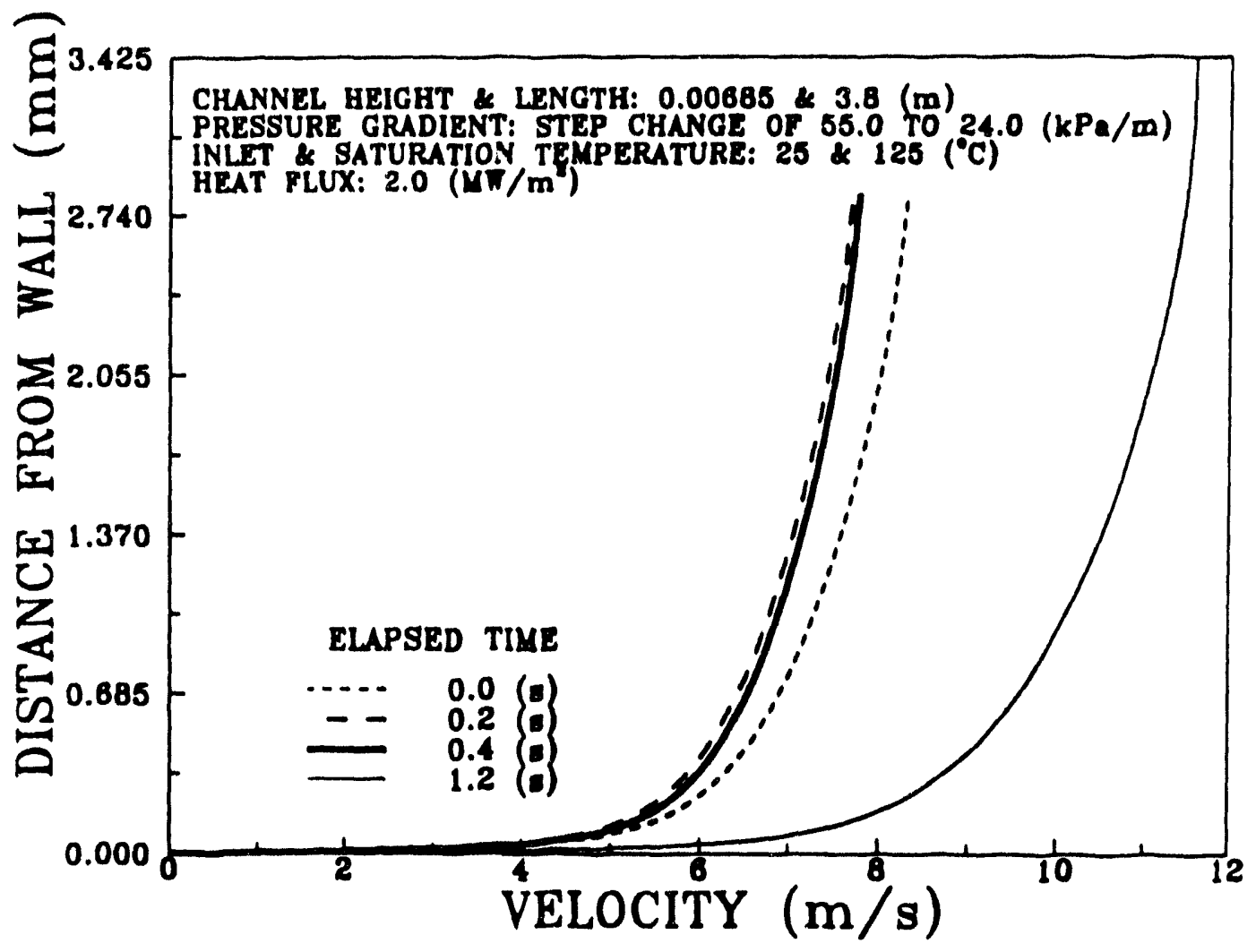


Fig. 4. Typical exit lemperature profiles as anction of time.

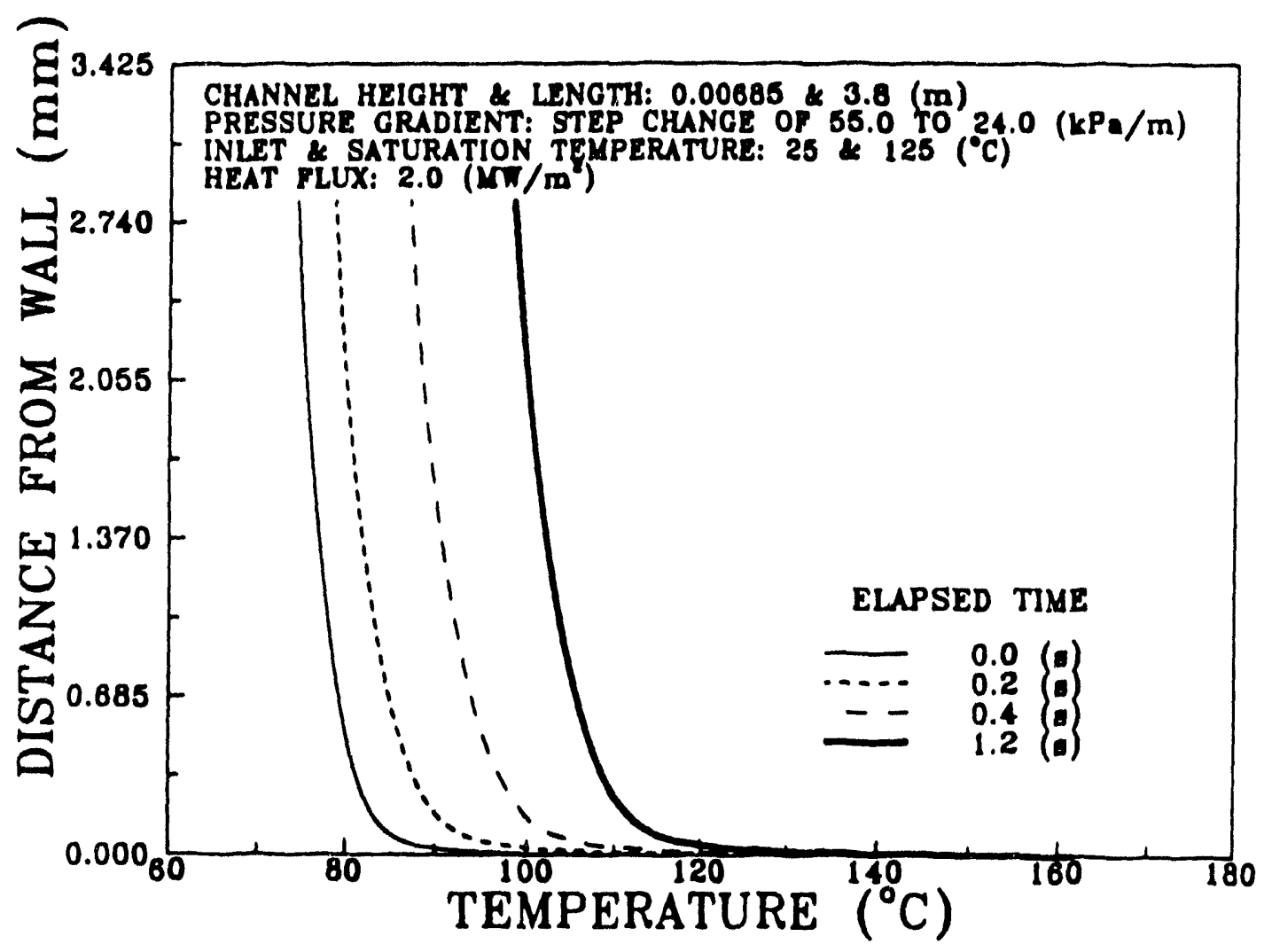


Fig. 5. Mean velocity variations for various heat nuxea with atep change of pressure gradient. OSV reached at end of each initial heat nux curve.

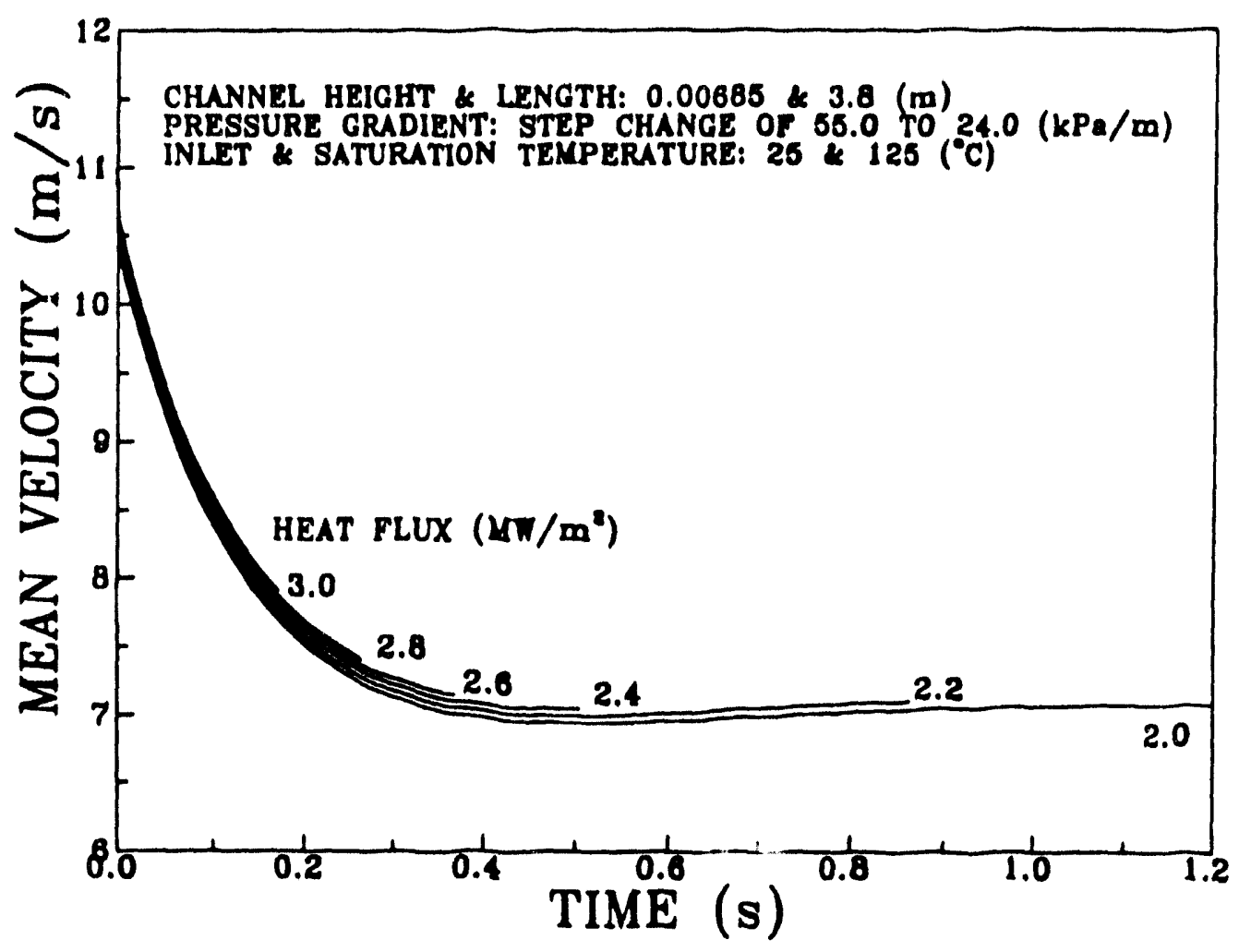


Fig. 6. Exit bulk temperature variation. for various heat lluxes with a step change of presaure gradient

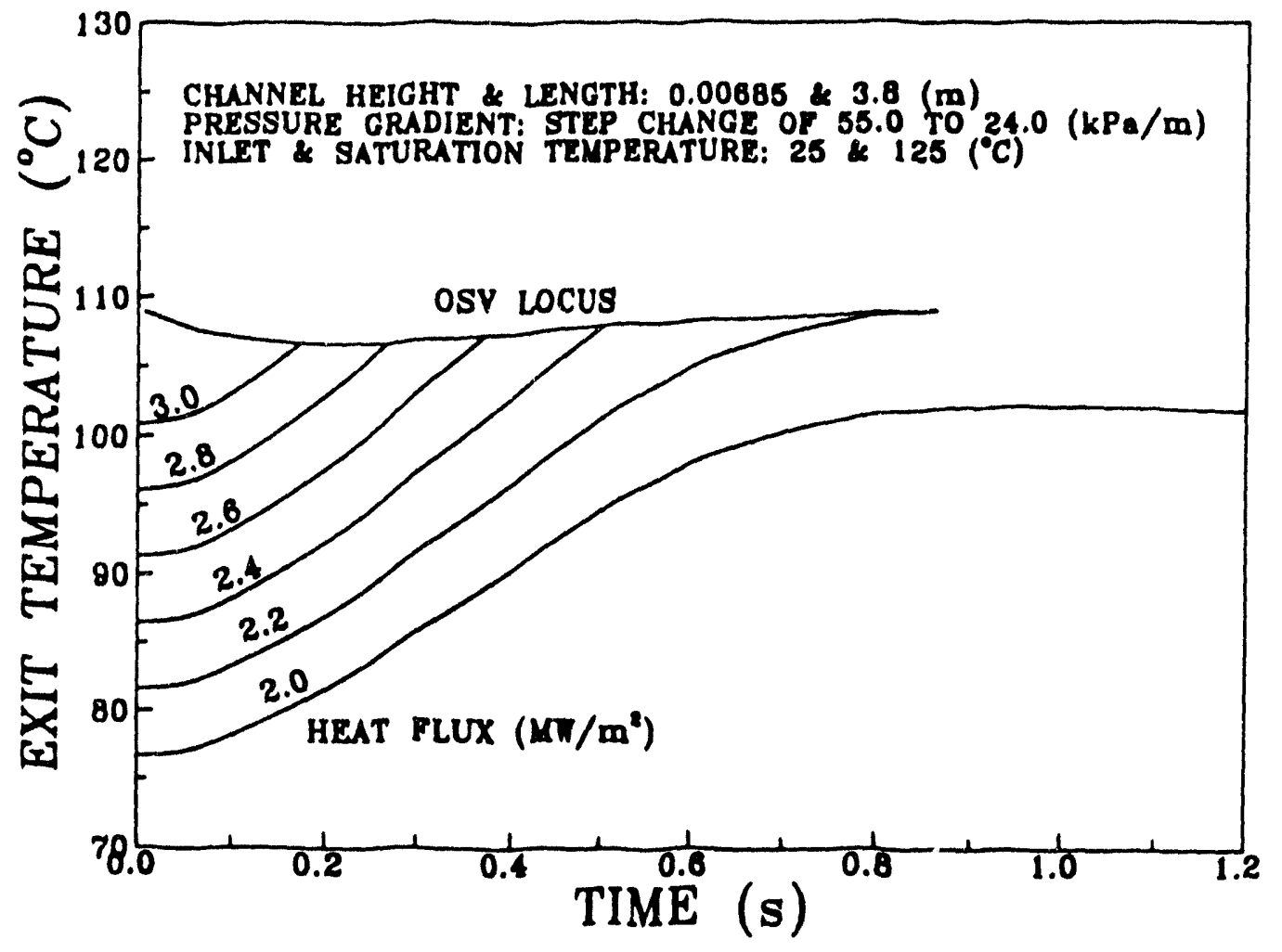




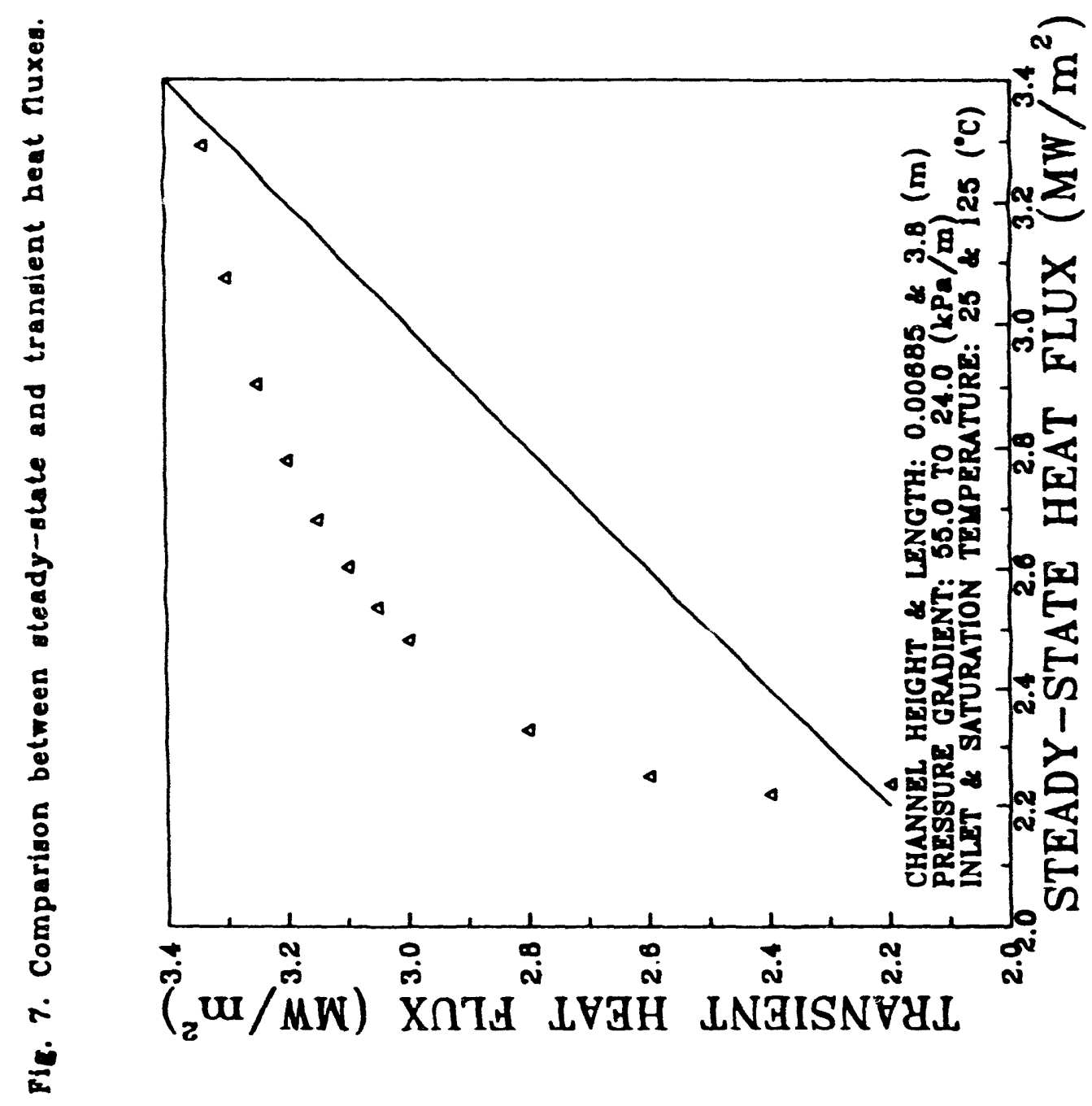


Fig. 8. Mean velocity variations for varioun ramp times $\left(q=3.0 \mathrm{k} / / \mathrm{m}^{2}\right)$

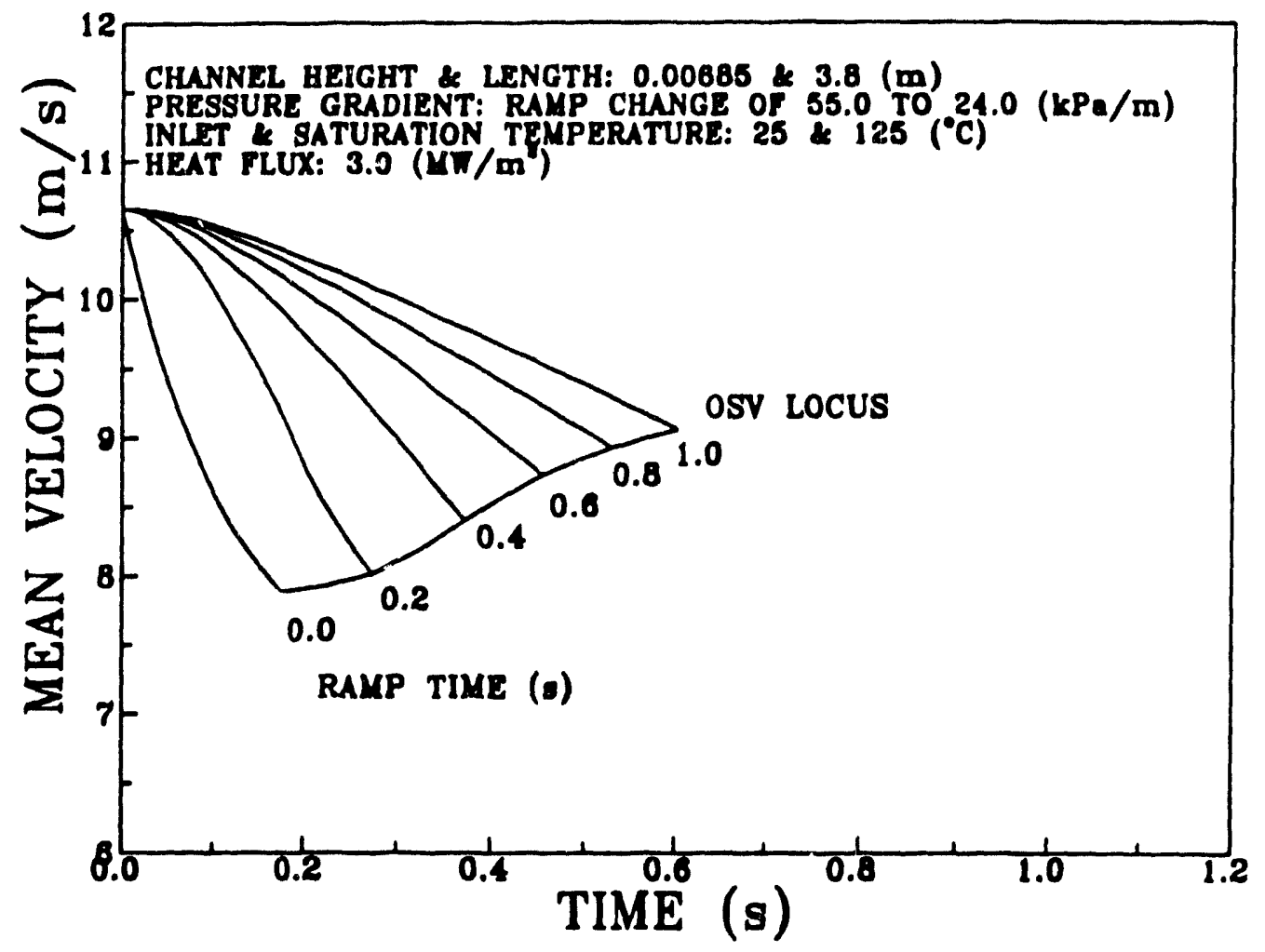


Fig. 9. Exil bulk temperature variation. for various ramp times $\left(q=3.0 \mathrm{MW} / \mathrm{m}^{2}\right)$

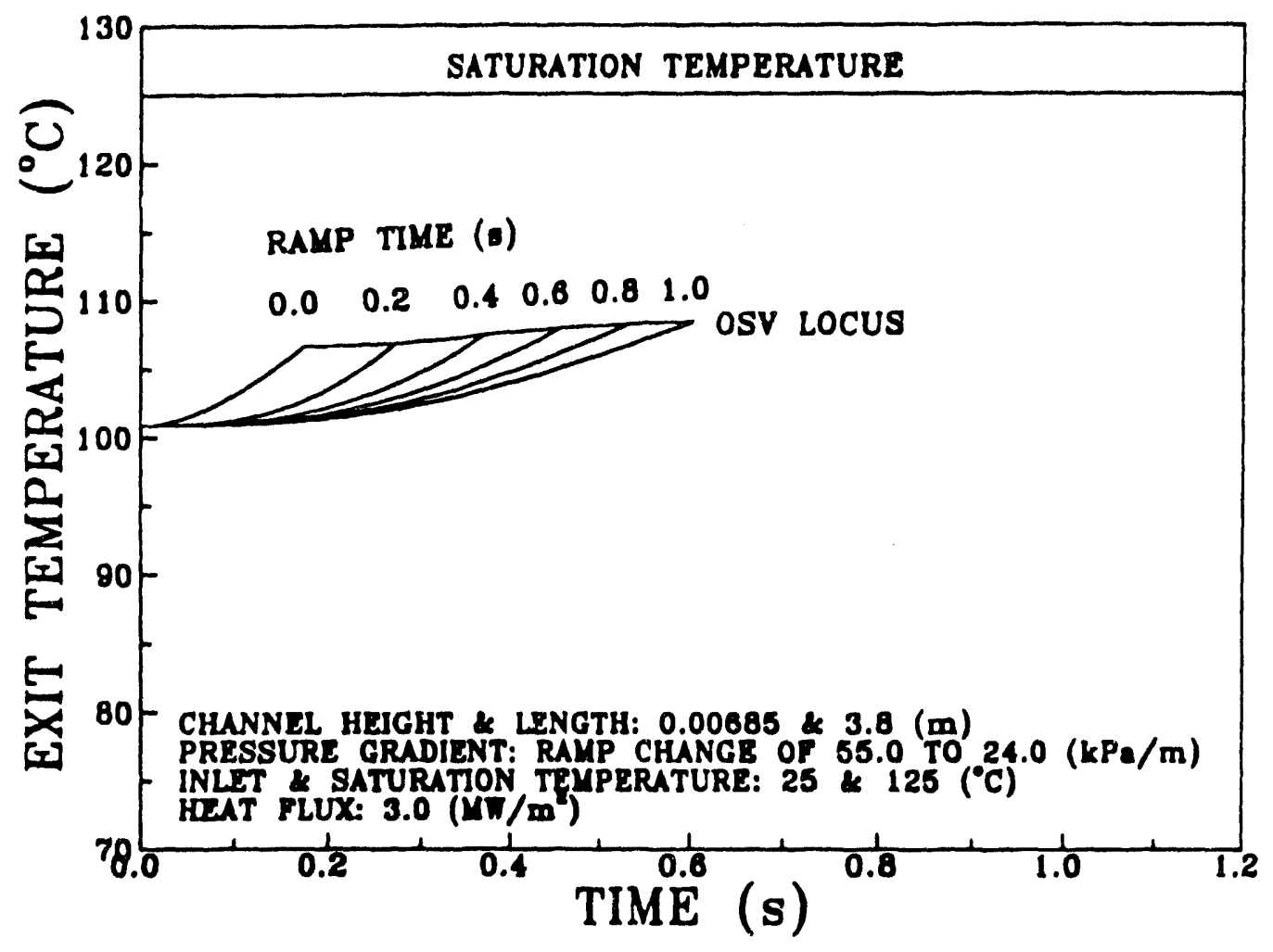


Fi. 10. Mean velocity variatione for various ramp times $\left(q=2.4 \mathrm{MW} / \mathrm{m}^{2}\right)$

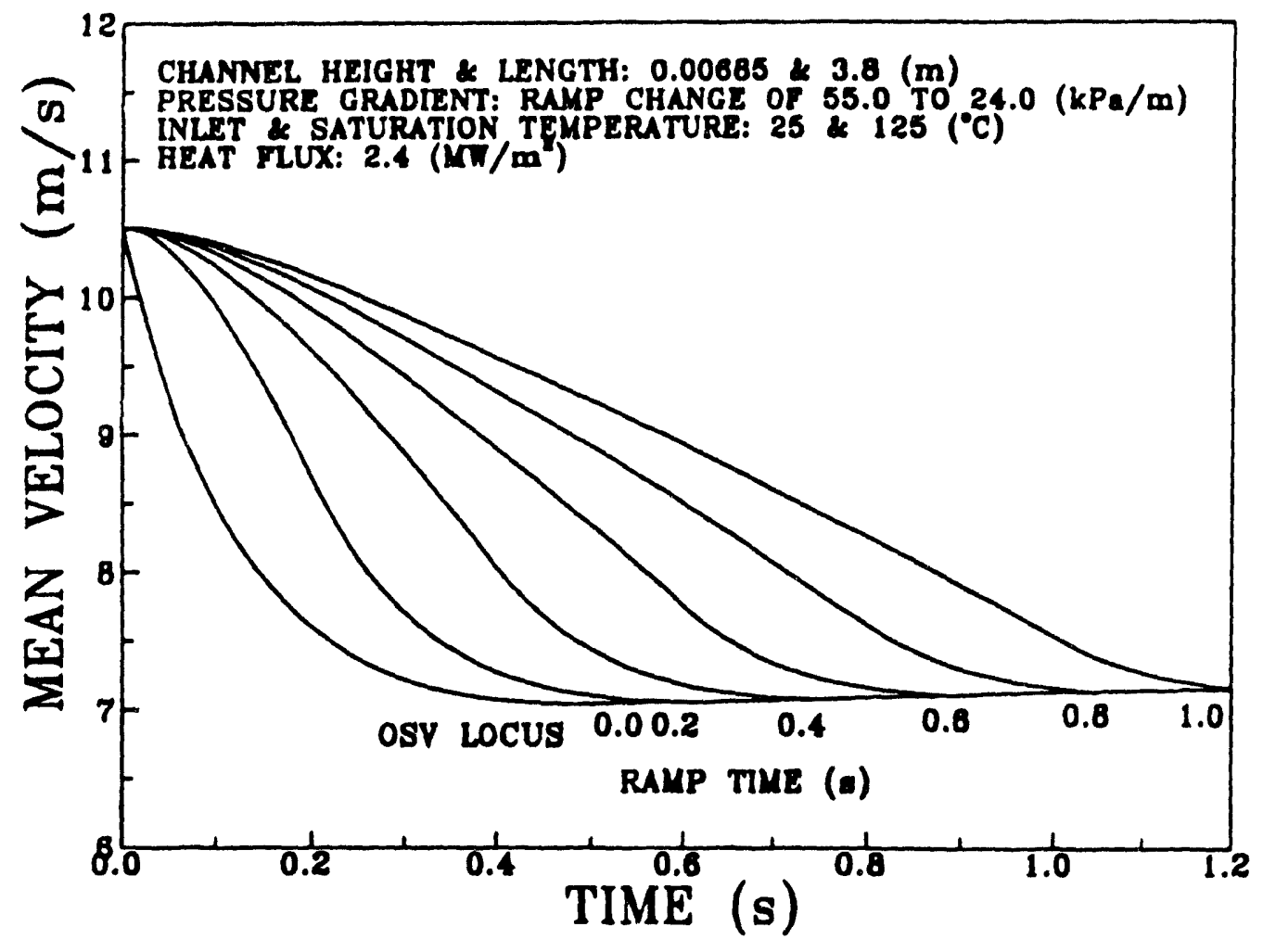


Fig. 11. Exit bulk temperature variation. for various ramp times $\left(q=2.4 \mathrm{MN} / \mathrm{m}^{2}\right)$

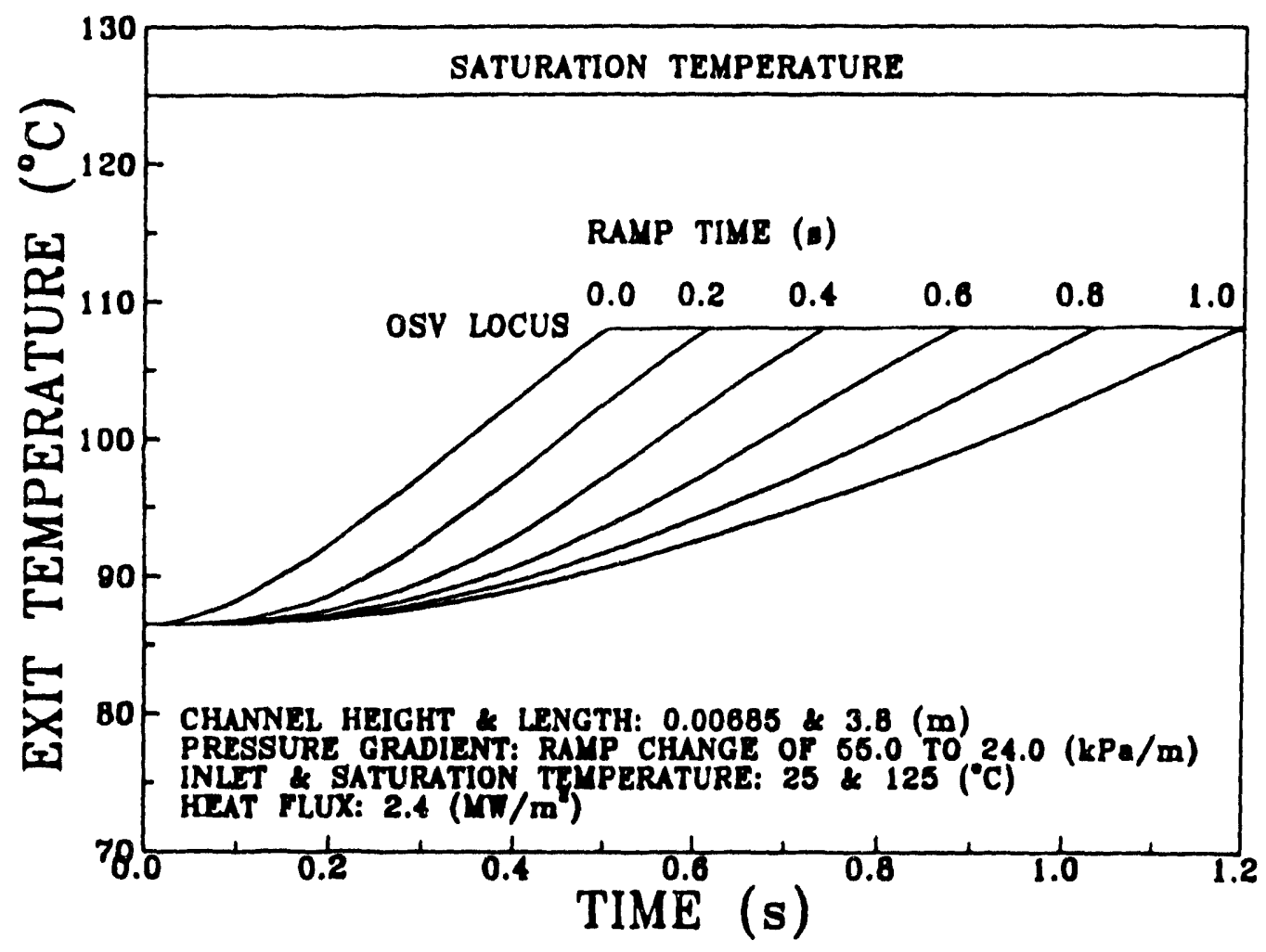


Fig. 12. Comparioon of numerical transient data with Equation (35).

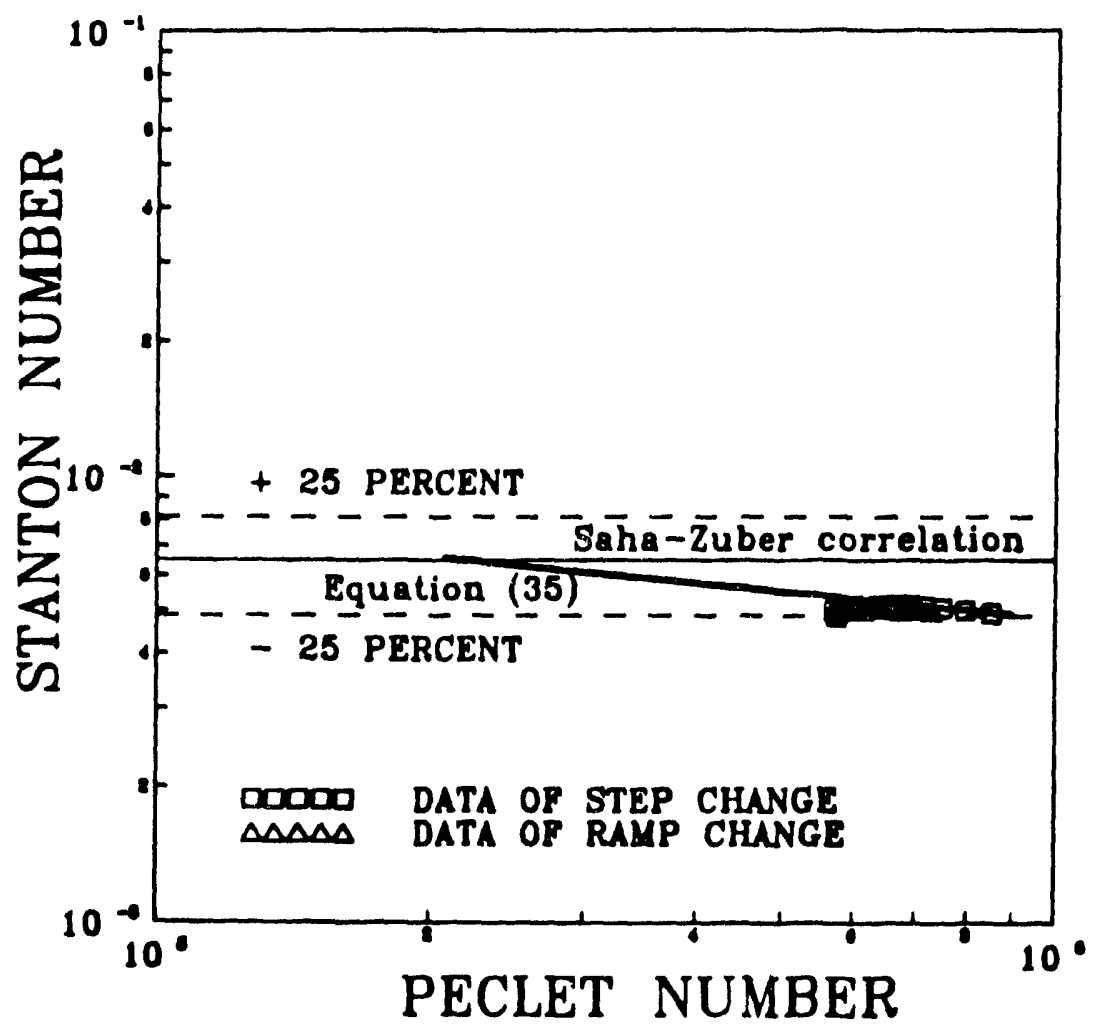



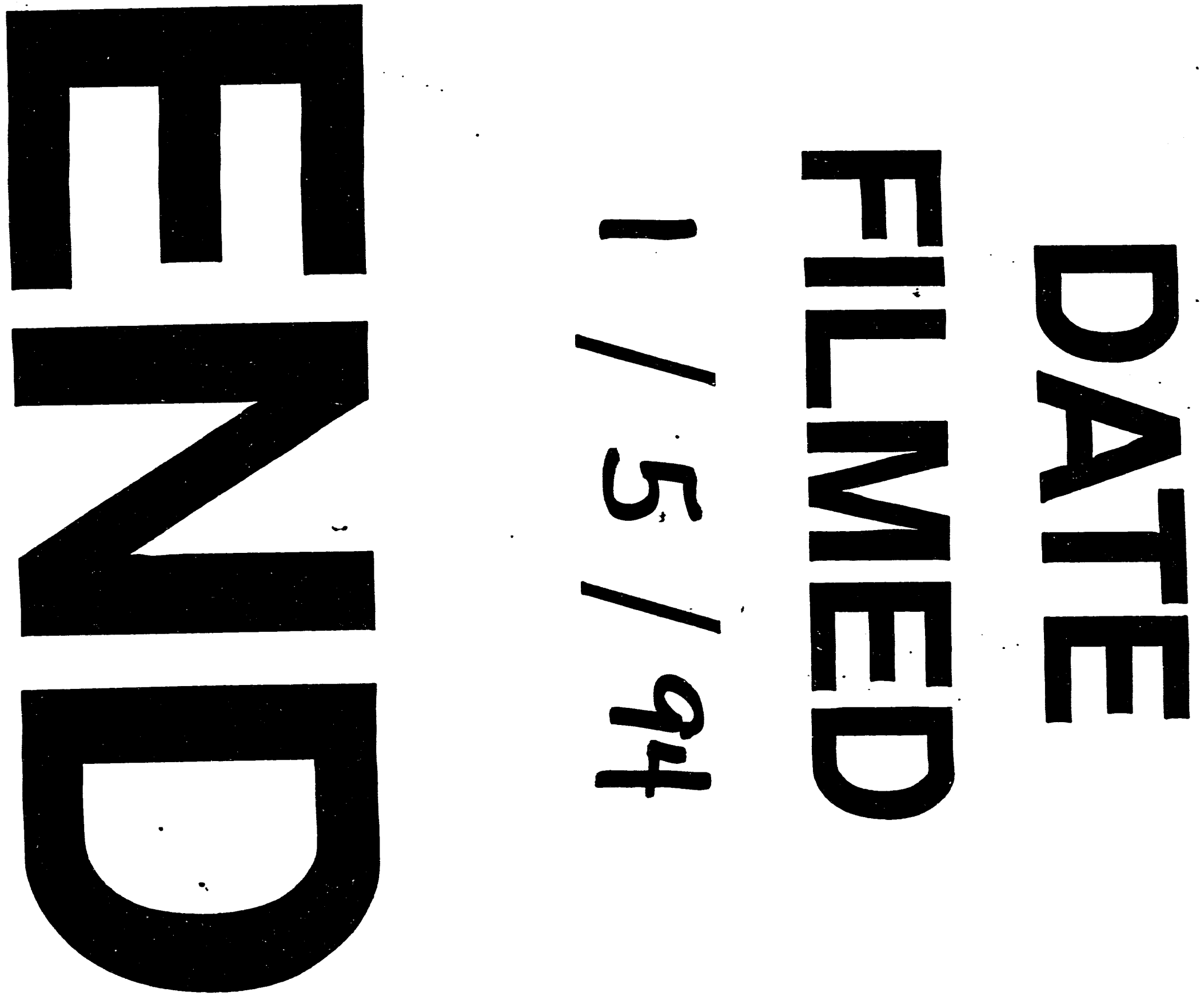
